\title{
ANN Model for Predicting Ultimate Shear Strength of Reinforced Concrete Corbels
}

\author{
Dr. Salim T. Yousif \\ Assistant Professor \\ E-mail:styousif59112@yahoo.com
}

\author{
Abdalkader A. Mohammed \\ Assistant lecturer \\ E-mail:abd_ali79@yahoo.com
}

\begin{abstract}
The artificial neural network (ANN) model was developed using previous experimental data on Reinforced concrete (RC) corbels to simulate the behavior of RC corbels. The neural netw,ork model has six input parameters representing the concrete compressive strength $\left(f_{c}\right)$, shear span (a), effective depth (d), corbel width (b), area of main reinforcement $\left(A_{s}\right)$, area of secondary reinforcement $\left(A_{h}\right)$, one output parameter representing the ultimate shear load $\left(\mathrm{V}_{\mathrm{u}}\right)$. A back propagation neural network (BPNN) with the log-sigmoid activation function is adopted due to its accuracy of prediction. The ANN model is constructed using the experimental data from the literature. The ANN predicted ultimate shear load which compared with those calculated by ACI31808 code Formula and Russo model. The neural network model is to predict the shear load of RC corbel more accurate than the ACI318-08 code Formula, and Russo model. Through the parametric studies using the ANN model, the effects of various parameters such as $\left(f_{c}^{\prime}, \mathbf{a}, \mathbf{d}, \mathbf{b}, \mathbf{A}_{s}\right.$, and $\left.\mathbf{A}_{h}\right)$ on the behavior of $\mathbf{R C}$ corbel were shown. The results reveal that the proposed network model captures the RC corbel underlying shear behavior very well.
\end{abstract}

KEY WORD: Artificial neural network, Corbel, Reinforced concrete, Shear Strength.

$$
\text { نموذج الشبكات العصبية للتبؤ بمقاومة القص القصوى للكتائف الخرسانية المسلحة }
$$

طور نموذج الثبكة العصبية باستخام نتائج عملية سابقة على الكتائف الخرسانية المسلحة لمحاكاة سلوكها.

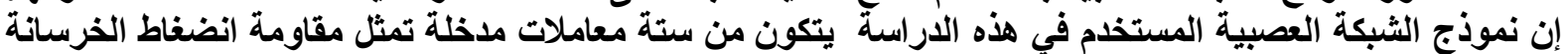

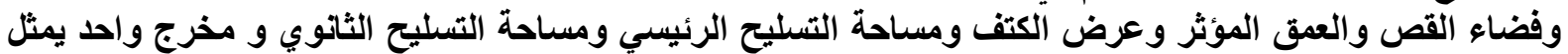

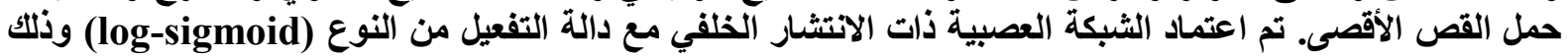

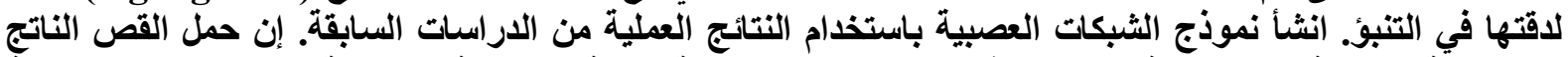

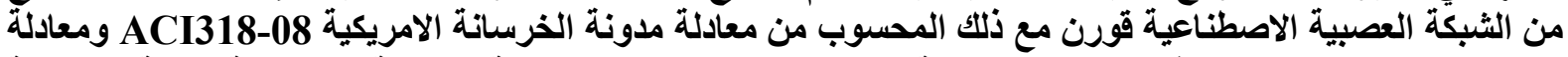

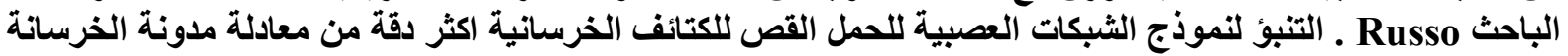

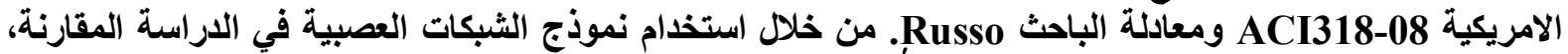

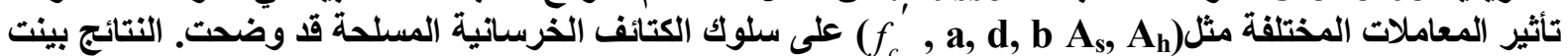
القدرة الجيدة لنموذج الثبكات العصبية للتبؤ بسلؤئ القص للكتائف الخرسانية المسلحة.

$$
\text { الكلمات الدالة: الثبكات العصبية الاصطناعية, الكتائف, الخرسانة المسلحة, مقاومة القص }
$$




\section{INTRODUCTION}

Corbels are brackets that project from the faces of columns and are used extensively in precast concrete construction to support primary beams and girders. Because of the prevalence of precast concrete, the design of corbels has become increasingly important. The term "corbel" is generally restricted to cantilevers having shear span-depth ratios less than unity such a small ratio causes the strength of corbels to often be controlled by shear, which is similar to deep beams Corbels are designed mainly to provide for the vertical reaction $\left(\mathrm{V}_{\mathrm{u}}\right)$ at the end of the supported beam, and sometimes they must also resist a horizontal force $(\mathrm{Nu})$ transmitted from the supported beam due to restrained shrinkage, creep, or temperature change (Fig. 1). Typically reinforcement for the corbel has consisted of primary tension steel $\left(A_{s}\right)$, horizontal hoops $\left(A_{h}\right)$, and framing bars $\left(A_{n}\right)$, (Fig. 1). In experimental, corbels display different types of failure, the most common of which are yielding of the tension reinforcement, crushing or splitting of the compression strut, and localized bearing or shearing failure under the loading plate [1].

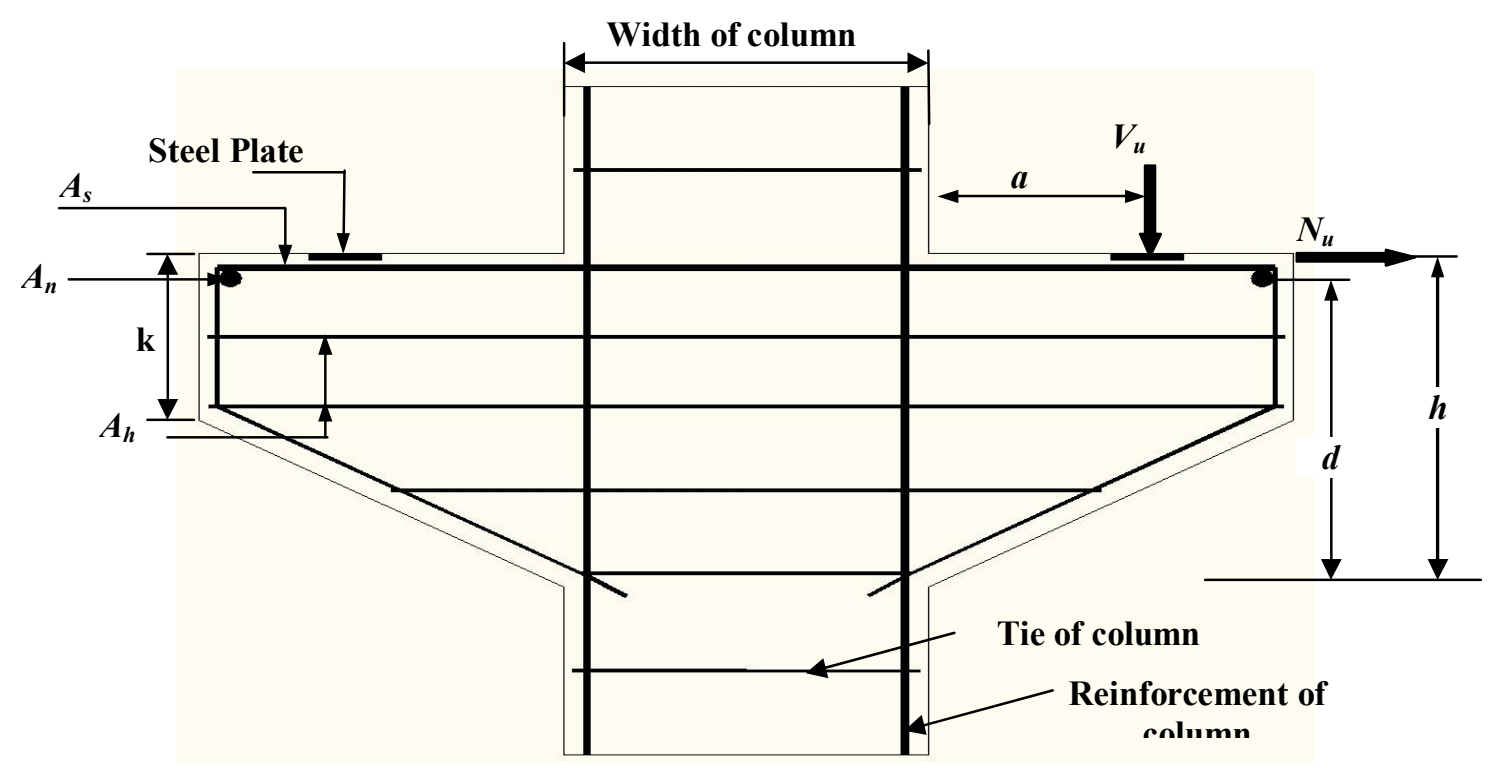

Fig. (1) Typical Reinforced Concrete Corbel

The analysis and design of non-flexural members, like dapped ended beams, corbels, deep beams, pile caps and openings in slabs, becomes difficult with ordinary flexural analysis as the true behavior of the member cannot be anticipated with the ordinary flexure theory. Different empirical approaches have been used for the design of such non-flexural members.

The ACI current design procedures for corbels are based on shear friction and empirical relationship based on the flexural capacity of the section [2]. The two basic equations allowed for design of the corbels by ACI318-08 are given as:

$V_{u}=\phi \mu A_{v f} f_{y}$

$V_{u}=\frac{M_{u}}{a}$

where

$M_{u}=\phi \mu A_{v f} f_{y}\left(d-\frac{A_{s t} f_{y}}{1.7 f^{\prime}{ }_{c} b}\right)$ 
The lesser of the two values is used for design. The ACI code further restricts the shear resistance of the section as:

$V_{u}<\phi f b d$

Where

$f=0.2 f^{{ }^{\prime}}{ }_{c}$ but not more than $5.5 \mathrm{MPa}$

Russo, et. Al., (2006) [3] proposed a model for determining the shear strength of reinforced concrete corbels based on superimposing the shear strength contribution of the strut-and-tie mechanism due to the cracked concrete and principal reinforcement, and the strength contribution due to stirrups. The design formula derived is:

$V_{u}=0.5\left(k \chi f^{\prime}{ }_{c} \cos \theta+0.65 \rho_{h} f_{y h} \cot \theta\right)$

Russo, et. Al., (2006) compared the proposed model with the ACI Code and the most recently proposed formulas, and he concluded that the proposed model is better because it provides the lowest COV values in all the comparisons. The formula proposed for design is adequately conservative and reliable. It leads to an almost constant safety factor (experimental-to-calculated shear strength ratio) differently from that provided by the ACI 318-02.

Recently, researchers have found the potential of artificial neural networks (ANNs) in the modeling of various engineering and natural systems. ANNs have been found very powerful in modeling systems governed by multiple variable interrelationships. The advantage of neural network modeling is that there is no need to know a priori the functional relationship among the various variables involved. The ANNs automatically built the relationships for a given network architecture as experimental data are processed through a learning algorithm. This approach is 'data driven', meaning that the network adapts to the training data presented to capture the relationship among input and output parameters. $[8,9]$ For this reason, ANNs should be interesting to researchers especially for engineers as a tool to support their task related to the modeling and prediction of behavior of engineering applications.

The principal aims of this paper are to develop multi-layered feed-forward neural networks trained with the back propagation algorithm to model the non linear relationship between different influencing parameters and the shear strength of reinforced concrete corbels, and to conduct a parametric study to establish the effects of different input parameters on the behavior of RC corbels using the trained ANN.

\section{OVERVIEW OF ARTIFICIAL NEURAL NETWORK}

Artificial neural networks (ANN), in recent years are more and more applied to solve various civil engineering problems. It is a tool suitable for the association of many parameters, through which certain material or strength features, such as the shear strength of reinforced concrete corbels, are identified. Neural network modeling technique has been successfully applied to many structural engineering problems, such as prediction of strength of concrete mix [4], prediction of shear strength of RC deep beams [5], modeling the capacity of pin-ended RC columns [7], Predicting Structural Properties of Elasto - Plastic Plates [8,9], Predicting Nonlinear Response of Uniformly Loaded Fixed Plates[10], predicting thickness of rectangular plates[11], and parameter identification in elasto-plastic plates [12].

ANN may be characterized as a computational model that is based on parallel distributed processing with particular properties such as the ability to learn, to generalize, to 
classify and to organize data [23]. There are two major neural network architectures: (1) feed forward; and (2) feed backward. Training of ANN could be supervised or unsupervised. Back propagation (BP) feed-forward multilayer perceptron is used extensively in engineering applications.

A Back propagation network in which each neuron has one output and as many input as the neurons in the previous layer is the most common one. The network input is connected to every neuron in the first hidden layer while each network output is connected to each neuron in the last hidden layer. In this case this would call full connection ANN. The network weights were originally set to random values and new values of the network parameters (weights) are computed during the network training phase. The neurons output are calculated using

$$
O_{i}=F\left(\sum_{j} I_{j} \times W_{i j}+b_{i}\right)
$$

Where $\boldsymbol{O}_{\boldsymbol{i}}$ is the output of the neuron $\boldsymbol{i}, \boldsymbol{I}_{\boldsymbol{j}}$ are the input of $\boldsymbol{j}$ neurons of the previous layer, $\boldsymbol{W}_{\boldsymbol{i}}$ are the neuron weights, $\boldsymbol{b}_{\boldsymbol{i}}$ is the bias for the modeling show (Equ.5), and $\boldsymbol{F}$ is the activation function. The activation function is the portion of the neural network where all the computing is performed. The activation function maps the input domain (infinite) to an output domain (finite). The range to which most activation functions map their output is either in the interval $[0,1]$ or the interval $[-1,1]$. There are several activation functions used over the years, however, the most common activation functions belong to five families as follows [13,14]: (1) linear activation function; (2) step activation function; (3) ramp activation function; (4) sigmoid activation function; and (5) Gaussian activation function. Figure 2 shows a typical neural network with one hidden layer. The ANN error $(\boldsymbol{E})$ for a given training pattern $\boldsymbol{i}$ is given by Eq. (6) where M is the size of training data, $\boldsymbol{O}_{\boldsymbol{j}}$ is the output and $\boldsymbol{T}_{\boldsymbol{j}}$ is the target.

$$
E=\frac{1}{M} \sum_{j=1}^{m}\left(O_{j}-T_{j}\right)^{2}
$$

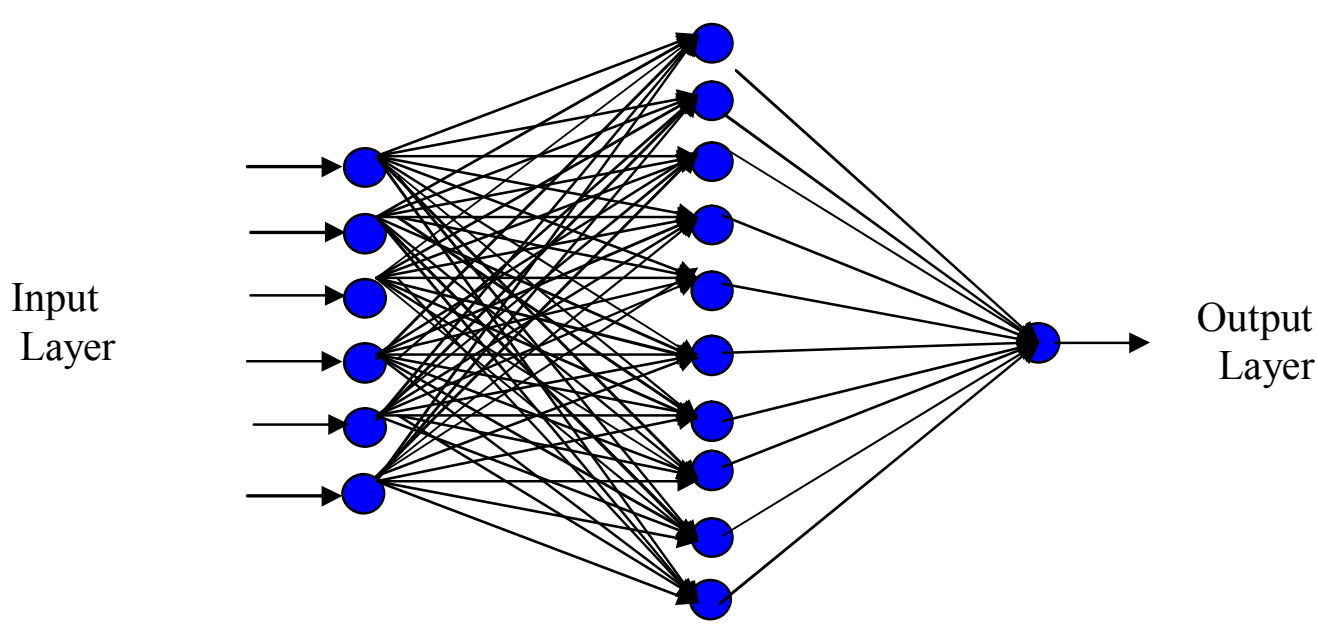

Hidden layer

Fig. (2) Typical neural network model 


\section{Database for Reinforced Concrete Corbels}

Seventy seven experimental data sets have been collected from previous studies [1522]. Seventy eight data sets are used in developing ANN model. Table (1) shows the range of maximum and minimum values of the parameters that are used in this study.

Table (1) Ranges of input parameters in database

\begin{tabular}{|l|c|c|}
\hline \multirow{2}{*}{} & \multicolumn{2}{|c|}{ Ranges } \\
\cline { 2 - 3 } & Minimum & maximum \\
\hline Concrete compressive strength $\left(f_{c}^{\prime}\right)(\mathrm{MPa})$ & 23.63 & 132 \\
\hline Corbel depth $(\mathrm{d})(\mathrm{mm})$ & 123.6 & 740 \\
\hline Shear Span $(\mathrm{a})(\mathrm{mm})$ & 50 & 450 \\
\hline Corbel width $(\mathrm{b})(\mathrm{mm})$ & 125 & 300 \\
\hline Area of primary reinforcement $\left(\mathrm{A}_{\mathrm{s}}\right)\left(\mathrm{mm}^{2}\right)$ & 101 & 3696 \\
\hline Area of stirrups reinforcement $\left(\mathrm{A}_{\mathrm{h}}\right)\left(\mathrm{mm}^{2}\right)$ & 32.25 & 790 \\
\hline Shear failure load $\left(\mathrm{V}_{\mathrm{u}}\right)(\mathrm{kN})$ & 124.4 & 1300 \\
\hline
\end{tabular}

\section{ARCHITECTURE OF NEURAL NETWORK}

In this work a multilayered feed-forward neural network with a back-propagation algorithm was adopted. The ANN was developed using the popular MATLAB software package [MATLAB R2009b] [13]. To train the ANN models, first the entire experimental data file was randomly divided into training and testing data sets. The sixty-three patterns were used to train the different network architectures. The remaining fourteen patterns were used for testing to verify the prediction ability of each trained ANN model. The network model was constructed. The model has six input parameters and one output parameter.

The rationale behind this is to study the significance of parameter on ultimate shear strength of reinforced concrete corbels. The models has two hidden layers with twelve nodes each, and output layer with one node giving ultimate shear strength of reinforced concrete corbels. Since the sigmoid function is used as transfer function, the inputs as well as the output are scaled in the range of (0.1-0.9). The convergence of the models in training is based on minimizing the error of tolerance for mean squared (MSE) error during the training cycles and monitoring the overall the performance of the trained networks by comparing the outputs. The architecture of the developed ANN model and its Properties are shown in Table (2). Levenberg-Marquardt

Table (2) Properties of ANN model

\begin{tabular}{|c|c|}
\hline Architecture & $6-12-12-1$ \\
\hline $\begin{array}{c}\text { Performance function in } \\
\text { terms of MSE }\end{array}$ & 0.000836 \\
\hline Learning Algorithm & Levenberg-Marquardt(LM) \\
\hline Activation Function & Logsig- Logsig- Logsig \\
\hline
\end{tabular}




\section{RESULTS AND DISCUSSION}

Table (3) represent the details of test data which used in ANN model, and the ratio of experimental ultimate shear load (Experimental (Exp.)) with computed value from analytical equations ( ACI-model; Russo-model), and ANN model. The median values for the ratio of the experimental failure load to calculate failure load (which calculated from the two analytical equations, ACI-model, and Russo-model), and that predicted by ANN model were founded to be $2.13,1.52$, and 0.98 , respectively. It can be concluded that both ACI, and Russo methods are more conservative, as these methods used factors of safety in calculating the shear strength of corbels.
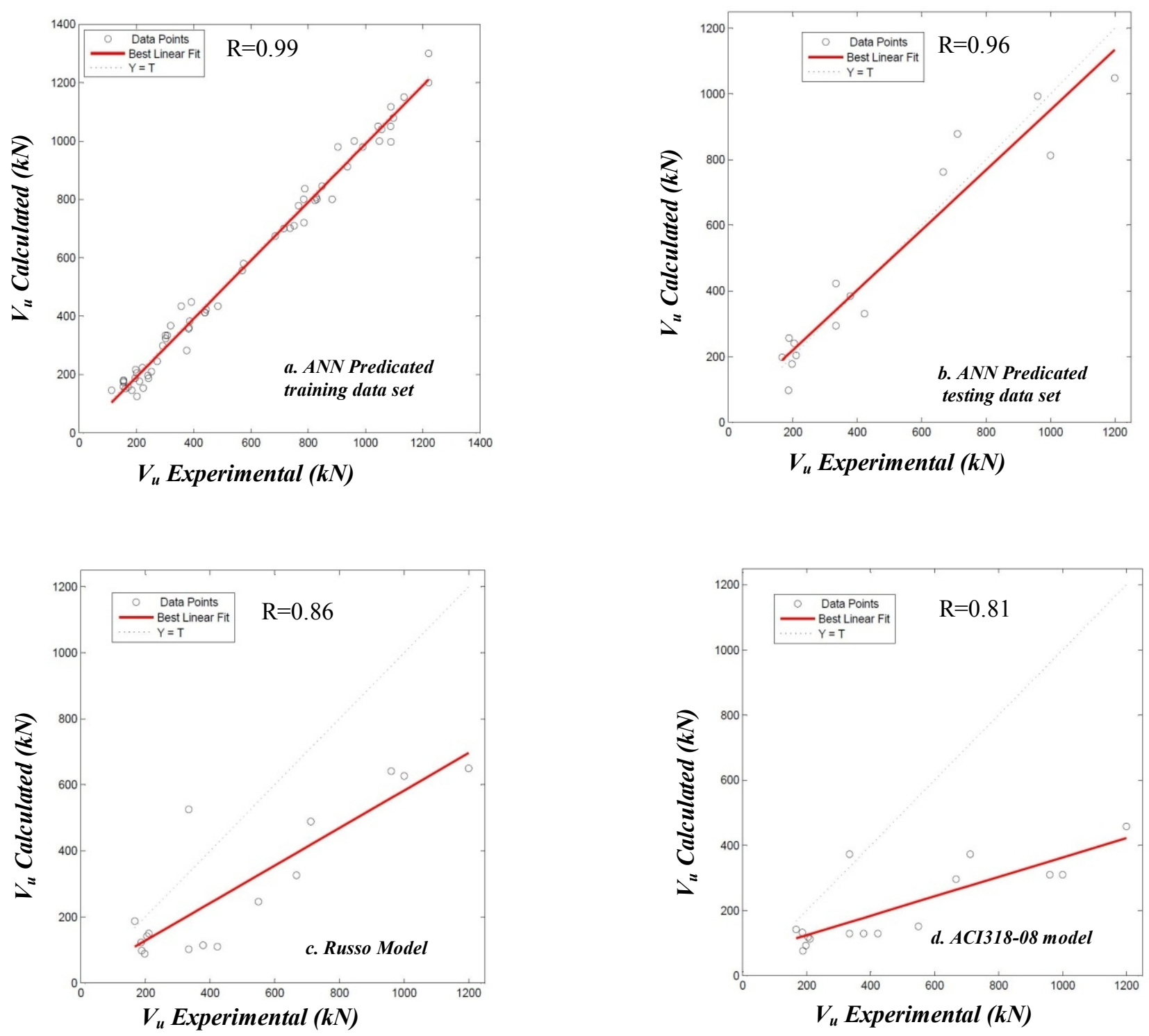

Fig.(3) Comparison of experimental and predicted ultimate shear load. a. ANN predicted training data set, b. ANN predicted testing data set, c. Russo Model, d. ACI318-08 Model. 
Table (3) Comparison with test results

\begin{tabular}{|c|c|c|c|c|c|c|c|c|c|c|c|c|c|}
\hline $\begin{array}{c}\text { Ref } \\
\text {. }\end{array}$ & $\begin{array}{l}\text { Corb } \\
\text { el no. }\end{array}$ & $\begin{array}{c}\mathrm{a} \\
(\mathrm{mm})\end{array}$ & $\begin{array}{c}\text { b } \\
(\mathbf{m m})\end{array}$ & $\begin{array}{c}\mathbf{d} \\
(\mathrm{mm})\end{array}$ & $\underset{(\mathrm{MPa})}{f_{c}^{\prime}}$ & $\begin{array}{c}\mathbf{A}_{\mathrm{s}} \\
\left(\mathbf{m m}^{2}\right)\end{array}$ & $\begin{array}{c}\mathbf{A}_{h} \\
\left(\mathrm{~mm}^{2}\right)\end{array}$ & $\begin{array}{c}f_{y s} \\
\text { (MPa) }\end{array}$ & $\begin{array}{c}f_{y h} \\
\text { (MPa) }\end{array}$ & $\begin{array}{c}V_{u} \\
(\mathbf{k N}) \\
\text { Exp. }\end{array}$ & $\begin{array}{c}V_{u} \\
\text { Exp. / } \\
\text { ANN } \\
\text { Model } \\
\end{array}$ & $\begin{array}{c}V_{u} \\
\text { Exp. / } \\
\text { Rus. } \\
\text { Model } \\
\end{array}$ & $\begin{array}{c}V_{u} \text { Exp./ } \\
\text { ACI } \\
\text { Model }\end{array}$ \\
\hline 18 & B2 & 140 & 254 & 356 & 48.6 & 387 & 284 & 420 & 420 & 667.2 & 0.87 & 2.04 & 2.25 \\
\hline 18 & E1 & 89 & 254 & 356 & 62.1 & 800 & 284 & 420 & 420 & 711.6 & 0.81 & 1.45 & 1.90 \\
\hline 18 & G1 & 267 & 254 & 356 & 61.4 & 1290 & 568 & 420 & 420 & 333.6 & 0.78 & 0.63 & 0.89 \\
\hline 19 & T8 & 89 & 150 & 123.6 & 44.6 & 226 & 158 & 420 & 420 & 188.4 & 0.73 & 1.93 & 2.46 \\
\hline 20 & SB1 & 250 & 150 & 740 & 56 & 1257 & 340 & 430 & 420 & 1200 & 1.14 & 1.84 & 2.62 \\
\hline 20 & SD1 & 300 & 125 & 600 & 95 & 1886 & 340 & 430 & 420 & 1000 & 1.23 & 1.59 & 3.23 \\
\hline 20 & PD2 & 200 & 150 & 500 & 71 & 1848 & 790 & 450 & 360 & 960 & 0.96 & 1.49 & 3.10 \\
\hline 21 & C9 & 130 & 160 & 140 & 48.5 & 158 & 114 & 440 & 380 & 197.5 & 1.11 & 2.24 & 2.13 \\
\hline 22 & TA-2 & 76 & 152 & 206 & 28.27 & 213 & 126.45 & 440 & 380 & 333.6 & 0.86 & 3.27 & 2.58 \\
\hline 22 & TB-3 & 76 & 152 & 206 & 33.64 & 213 & 142 & 440 & 440 & 378.1 & 1.14 & 3.31 & 2.92 \\
\hline 22 & SC-2 & 76 & 152 & 206 & 38.3 & 180 & 32.25 & 999.7 & 413.6 & 422.6 & 1.27 & 1.11 & 0.95 \\
\hline 23 & B3 & 228 & 152.4 & 225 & 25.75 & 638.7 & 129 & 372 & 440 & 187 & 0.94 & 1.52 & 1.411 \\
\hline 23 & $\mathrm{C} 3$ & 230 & 152.4 & 225 & 30 & 1058 & 258 & 345 & 450 & 167.2 & 0.69 & 0.89 & 1.18 \\
\hline 23 & E2 & 101 & 127 & 225 & 30.48 & 600 & 96.7 & 412 & 460 & 204.6 & 0.85 & 1.44 & 1.73 \\
\hline 23 & $\mathrm{H} 3$ & 152 & 127 & 225 & 26.4 & 851.6 & 225.8 & 460 & 435 & 210.8 & 1.03 & 1.41 & 1.86 \\
\hline & & & & & & & & & & $\begin{array}{c}\text { Medi } \\
\text { an }\end{array}$ & 0.98 & 1.52 & 2.13 \\
\hline
\end{tabular}

The accuracy of the predicted ANN values of the ultimate shear load is shown in Fig. $(3 \mathrm{a}-\mathrm{b})$, this model, predict the training sets and testing sets quite well. Figures (3c, and $3 \mathrm{~d}$ ) show the predicted values versus experimental values of ultimate shear load for corbels using formulas proposed by the ACI-Model, and Russo model, respectively. The coefficients of correlation, R, were (0.96), (0.86), and (0.81) for the ANN model, Russo -model, and ACImodel, respectively. From these results, it can be seen that the neural network model predict the shear strength more accurately than other two models and concluded that the neural network model can successfully predicted the shear failure load for reinforced concrete corbels, on the other hand, the ANN model shows least scattering of the results.

\section{PARAMETRIC STUDY}

One of the advantages of neural network models is that parametric studies can be easily done by simply varying one input parameter and all other input parameters are set to constant values. Through parametric studies, it can verify the performance of model in simulating the physical behavior of reinforced concrete corbels, due to the variation in a certain parameter values.

\section{1- Effect of Corbel Depth.}

The effect of corbel depth on ultimate shear strength is illustrated in the Figs. (4-8). Regardless of other parameters the figures show that the ultimate shear strength of corbels increases $(70 \%)$ with increasing the corbel depth from $150 \mathrm{~mm}$, to $700 \mathrm{~mm}$. Also the figures indicated that the increasing of ultimate shear strength decreases to reach $(8 \%)$ when the depth of the corbel changes from $500 \mathrm{~mm}$, to $700 \mathrm{~mm}$. This fact is due to the effect of slenderness coefficient which is become clearer when the depth increases.

\section{2- Effect of Shear Span.}

Fig. (4) shows the effect of shear span on the ultimate shear strength of the corbels. It can be seen that the shear strength decrease with increasing the shear span and its effects become more obvious as depth increases. When the shear span increasing from $150 \mathrm{~mm}$ to $350 \mathrm{~mm}$, the shear strength decrease in $(72.5 \%)$ for depth equal to $150 \mathrm{~mm}$, while the shear 
strength decrease (78\%) for depth equal to $700 \mathrm{~mm}$. On the other hand the corbels with small shear span shows more deeply affected by the corbel depth.

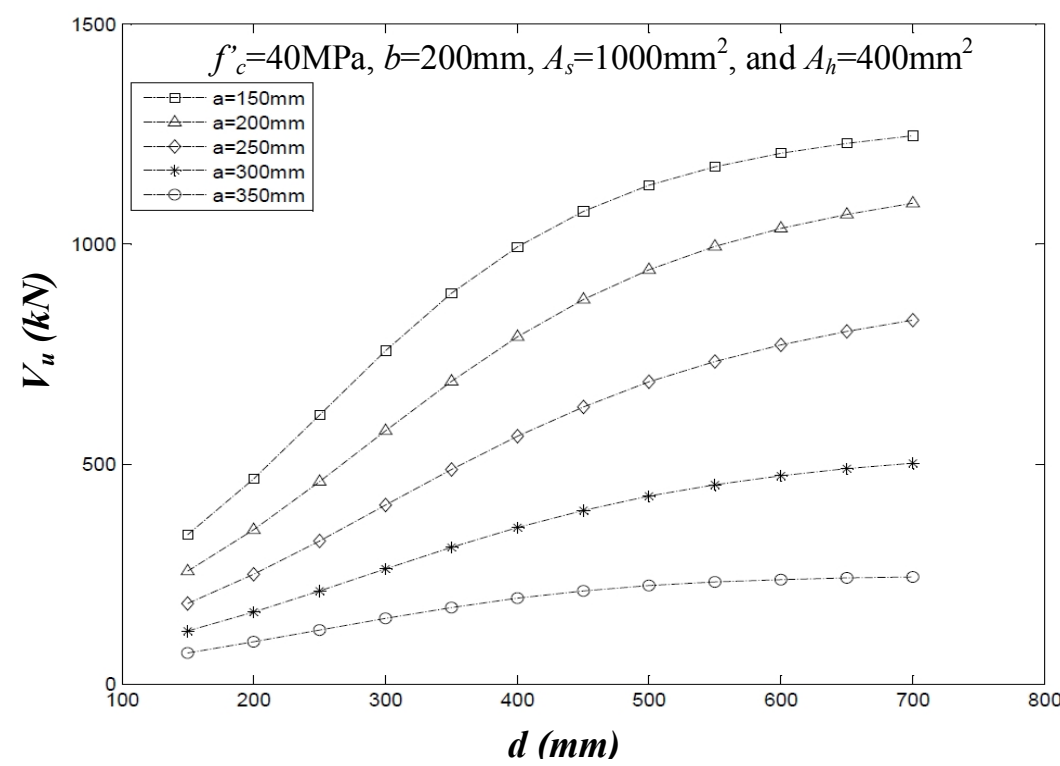

Fig. (4) Ultimate shear strength versus corbel depth for different values of shear span (a).

\section{3- Effect of Concrete Compressive Strength.}

Fig. (5) illustrated the relationship between the ultimate shear strength and the depth of corbels for different values of compressive strength. The range of compressive strength values was $25-85 \mathrm{MPa}$. When the other parameters kept constant as shown in figure, the shear strength is increasing with increase of compressive strength. At the small depth of corbel the difference between shear loads is obvious, but when the corbel depth increases this difference is decreased. When the compressive strength increase from $25 \mathrm{MPa}$ to $85 \mathrm{MPa}$, the increase in shear strength is $(60.7 \%)$, and $(7.5 \%)$ for corbel depth $150 \mathrm{~mm}$, and $700 \mathrm{~mm}$, respectively.

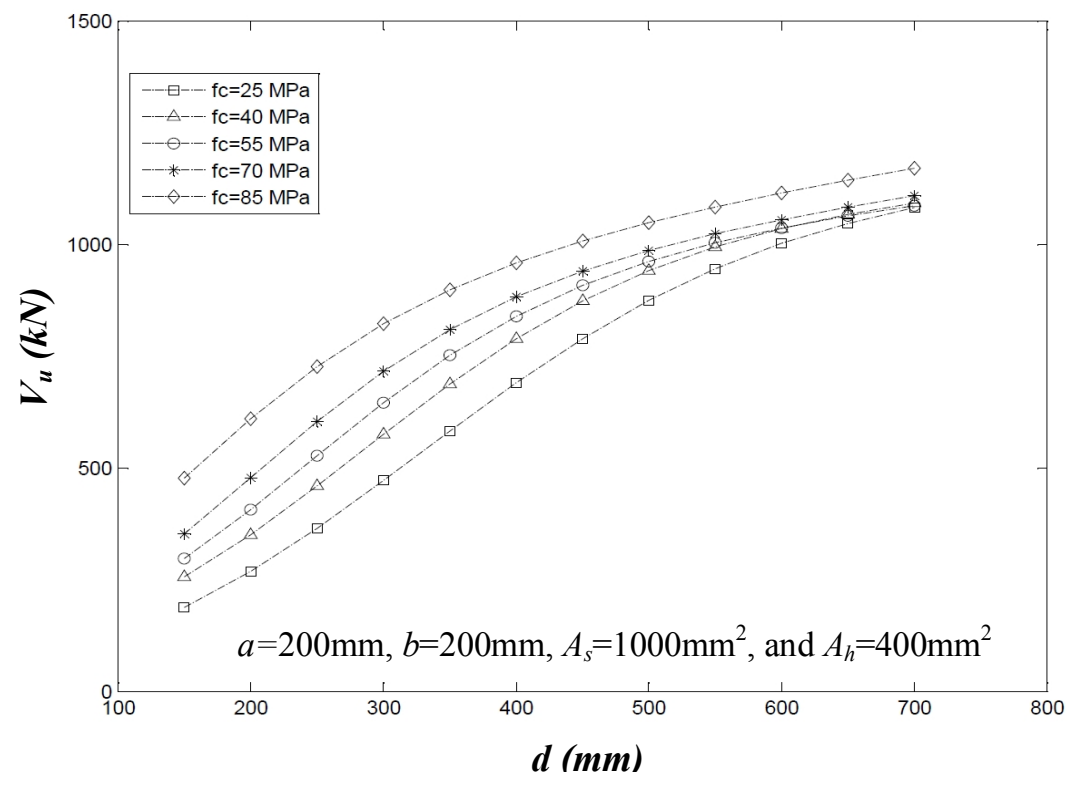

Fig. (5) Ultimate shear strength versus corbel depth for different values of compressive strength $1\left(\hat{9}_{c}^{\prime}\right)$. 


\section{4- Effect of Corbel Width.}

Fig. (6) shows the effect of corbel width on the shear load. It can be seen from the figure that the influence of corbel width is small and the curves are parallel in the most its portions.

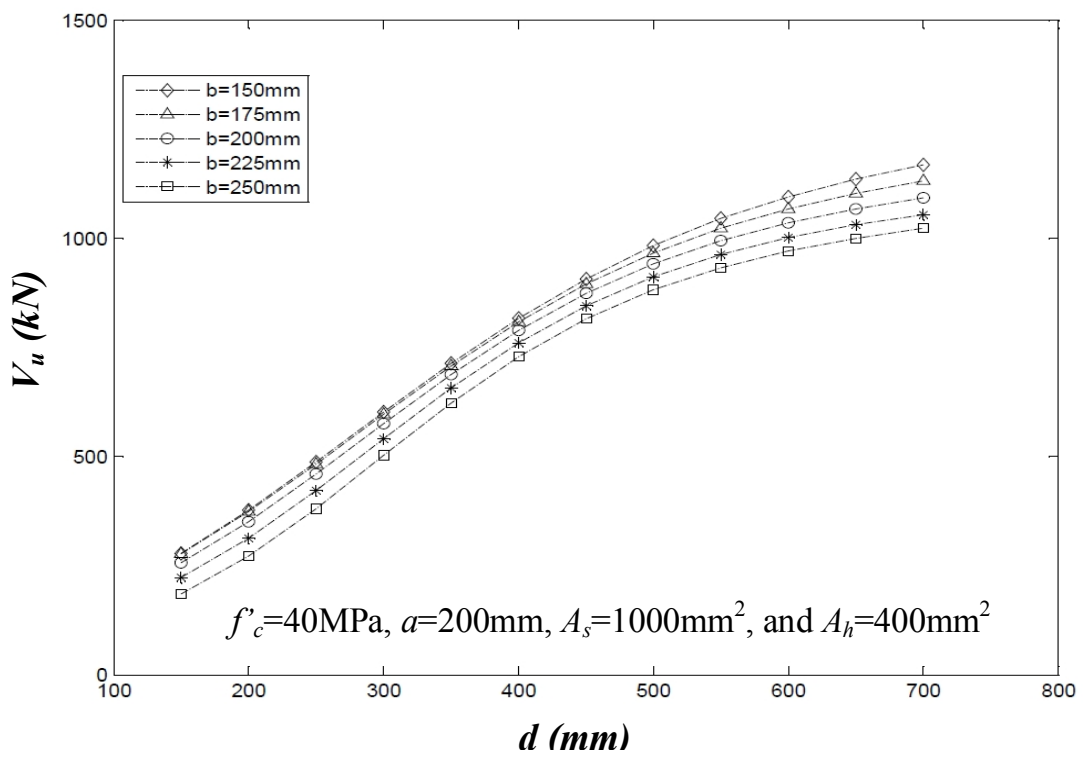

Fig. (6) Ultimate shear strength versus corbel depth for different values of corbel width (b).

\section{5- Effect of Main Reinforcement.}

Effect of main reinforcement area $\left(A_{s}\right)$ on the ultimate shear strength is illustrated in Fig. (7). The range of main reinforcement used in parametric study is illustrated in Table (3). There is again an almost nonlinear increase in failure load of corbels with increasing of main reinforcement. For corbel depth $150 \mathrm{~mm}$, there is no indicated difference between the ultimate loads for the different values of area of reinforcement as shown in the figure. But the difference between the failure load can be recognized for corbel depth equal to $700 \mathrm{~mm}$, the increase in ultimate load is $(14.5 \%)$, when increasing the area of main reinforcement from $\left(500 \mathrm{~mm}^{2}\right)$ to $\left(2500 \mathrm{~mm}^{2}\right)$. On the other hand the effect of the main reinforcement on the shear strength inverted when the depth of the corbel increased more than $450 \mathrm{~mm}$, and on the whole, the effect of main reinforcement not significant in the ultimate shear loads.

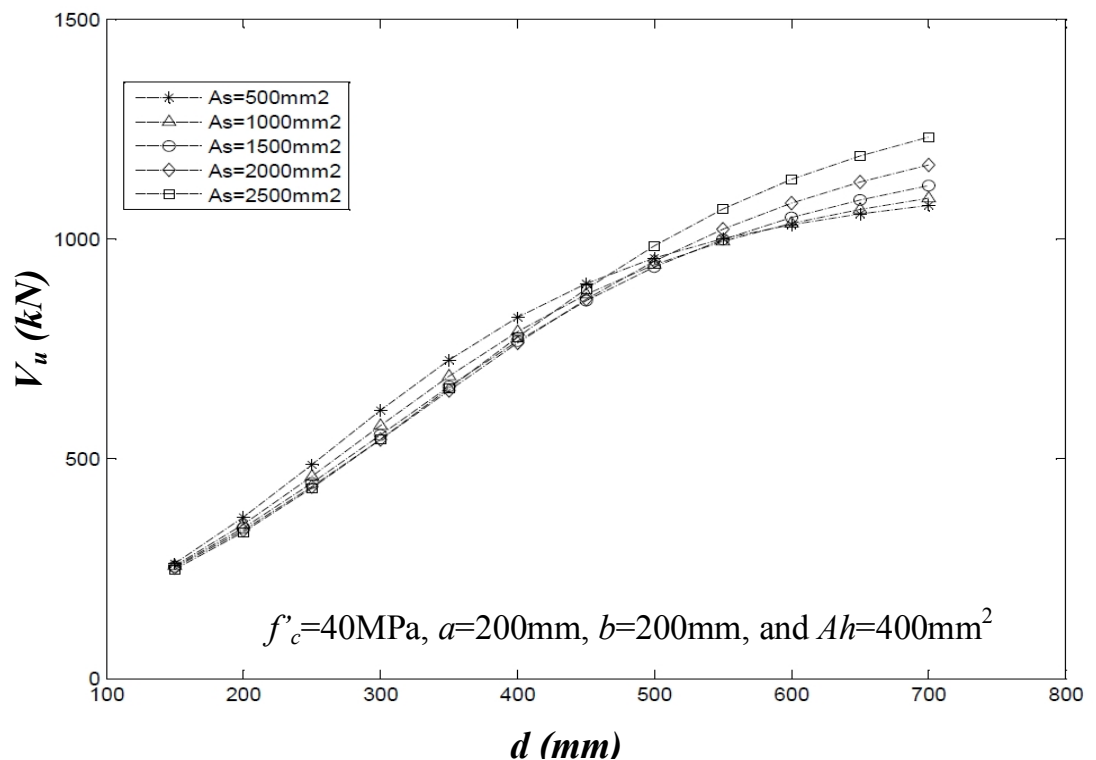

Fig. (7) Ultimate shear strength versus corbel depth for different values of main reinforcement $\left(A_{\mathrm{s}}\right)$. 


\section{6- Effect of Secondary Reinforcement.}

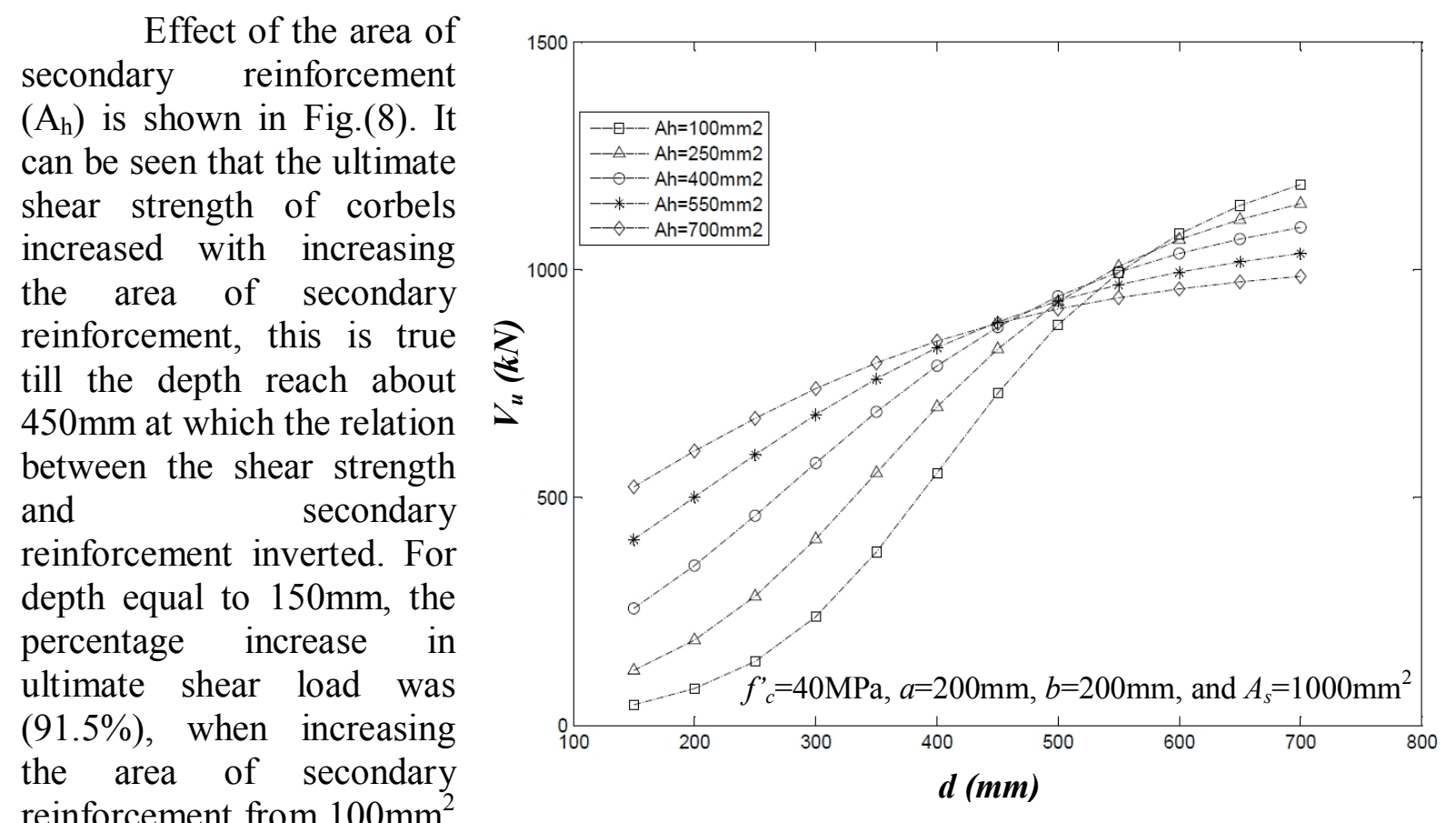
reinforcement from $100 \mathrm{~mm}^{2}$ to $700 \mathrm{~mm}^{2}$, respectively. While for depth equal to $700 \mathrm{~mm}$, the percentage increase in ultimate shear strength was (17\%), when decreasing the area of secondary reinforcement from $700 \mathrm{~mm}^{2}$ to $100 \mathrm{~mm}^{2}$ respectively.

\section{CONCLUSIONS}

In this study, the ANN model was developed to simulate the behavior of reinforced concrete corbels. A back-propagation neural network (BPNN) was used. The measured experimental values are compared with the shear strength calculated from ANN model, the ACI318-08 code formula and Russo model. A parametric study was carried out to explain the effects of various parameters on the behavior of reinforced concrete corbels. It can be concluded from this study the following:

- The ANN model is stronger and valid to simulate the behavior of reinforced concrete corbels, the ANN predictions are accurate provided that the input data are within the ranges used for training the network.

- ANN algorithm is an effective and inexpensive tool for carrying out parametric study among several parameters that affect physical phenomenon in engineering as demonstrated for the case of ultimate shear load of reinforced concrete corbels.

- From parametric study the corbel depth, compressive strength of concrete and shear span are the major factors effect on the behavior of reinforced concrete corbels. 


\begin{tabular}{|l|l|}
\hline \multicolumn{2}{|l|}{ Notations } \\
\hline$A_{h}$ & Overall area of horizontal stirrups. $\mathrm{mm}^{2}$. \\
\hline$A_{n}$ & Area of principal reinforcement required for resisting horizontal force $(\mathrm{Nu}) . \mathrm{mm}^{2}$. \\
\hline$A_{s}$ & Overall area of principal reinforcement, $\mathrm{mm}^{2}$. \\
\hline$A_{v f}$ & $=A_{s}+A_{h}, \mathrm{~mm}^{2}$. \\
\hline$a$ & Shear span length, $\mathrm{mm}$. \\
\hline$b$ & Width of corbel, $\mathrm{mm}$. \\
\hline$d$ & Effective depth of corbel, $\mathrm{mm}$. \\
\hline$E_{c}, E_{s}$ & Elastic modules of concrete and steel, respectively. $M P a$. \\
\hline$f^{\prime}{ }_{c}$ & Cylindrical concrete compressive strength. $M P a$. \\
\hline$f_{y h}, f_{y}$ & $\begin{array}{l}\text { Yielding strength of horizontal stirrups and principal reinforcement, respectively. } \\
\text { MPa. }\end{array}$ \\
\hline$h$ & Overall depth of corbel, $\mathrm{mm}$. \\
\hline$k$ & A dimensional (with respect to $d$ ) depth of compressive zone, $\mathrm{mm}$. \\
\hline$N_{u}$ & Ultimate horizontal action applied at top of corbel, $\mathrm{kN}$. \\
\hline$V_{u}$ & Ultimate shear strength for corbel, $\mathrm{kN}$. \\
\hline$\rho_{h}$ & Stirrups reinforcement ratio at column corbel interface. $\left(A_{h} / \mathrm{bd}\right.$ ) \\
\hline$\chi$ & A dimensional interpolating function (Ref. 3, Eq. $(31)$ ). \\
\hline$\theta$ & Angles between strut and vertical direction in corbels with stiruups. ( $\mathrm{radian}$ ) \\
\hline
\end{tabular}

\section{REFRENCES}

1. Hwang S., J, Lu W., Y, and Lee H., J, "Shear Strength Prediction for Reinforced Concrete Corbels", ACI Structural Journal, V. 97, No. 4, Jul.-Aug. 2000.

2. ACI Committee 318-08, "Building Code Requirements for Structural Concrete (ACI 318-08) and Commentary (ACI 318R-08)," American Concrete Institute, Farmington Hills, Mich., 2008, Appendix A.

3. Russo G., Venir R., Pauletta M., and Somma G., "Reinforced Concrete CorbelsShear Strength Model and Design Formula", ACI Structural Journal, Vol. 103, No. 1, Jan.-Feb. 2006, pp

4. S. T. Yousif and S. M. Abdullah, "Artificial Neural Networks Model for Predicting Compressive Strength of Concrete". Tikrit Journal of Eng. Sciences ,Vol.16 , No.3 ,September 2009, pp.55 - 63.

5. Sanad A, Saka MP. "Prediction of Ultimate Shear Strength of Reinforced Concrete Deep Beams using Neural Networks. Journal of Structural Eng”, ASCE vol. 127 ,No. 7, 2001, pp. 2495-2505.

6. Andres W. C. Oreta, "Simulating Size Effect on Shear Strength of RC Beams without Stirrups Using Neural Networks", Engineering Structures Vol. 26, No. , 2004, PP 681-691.

7. Chuang $\mathrm{PH}$, Goh ATC, Wu X. Modeling the capacity of pin ended slender reinforced concrete columns using neural networks. J Struct Eng, ASCE 1998.

8. A. A. Abdul- Razzak and S. T. Yousif "Artificial Neural Network Model for Predicting Structural Properties of Elasto-Plastic Plates." , Fourth Jordanian Civil Engineering Conference, Structural-Geotechnical Engineering and Construction Management, 10-13 April (2006) Amman and Dead Sea, Jordan".

9. Yousif and A. A. Abdul-Razzak "Analysis of Elsto-Plastic Plates using Artificial Neural Networks" , The Ninth International Conference on the Application of 
Artificial Intelligence to Civil, Structural and Environmental Engineering., Malta 18-21 September 2007

10. A. A. Abdul-Razzak and S. T. Yousif "Artificial Neural Network Model for Predicting Nonlinear Response of Uniformly Loaded Fixed Plates." Eng. \& Technology, Vol.25, No.3, 2007, pp 334-348.

11. A. A. Abdul-Razzak and S. T. Yousif " Artificial Neural Networks Model for Predicting Thickness of Rectangular Plates.", International Conference on Innovative and Smart Structural Systems for Sustainable Habitat (INSHAB -2008) .Coimbatore,03-05 January 2008

12. S. T. Yousif and A. A. Abdul-Razzak, "Parameter Identification in Elasto-Plastic Plates using Neural Networks.", Proceedings of the Third International Conference on Modeling Simulation and Applied Optimization (ICMSAO'09), Sharjah, U.A.E January 20-22 2009

13. The math works, MATLAB R2009b, 24 Prime way, Natick, MA 01760-1500, USA, 2009.

14. Gomes H.M., Awruch A.M., "Comparison of Response Surface and Neural Network with Other Methods for Structural Reliability Analysis", Struct. Saf. Vol. 26,2004,pp.49-67. 